\title{
PRÁTICAS PEDAGÓGICAS E AS TECNOLOGIAS DIGITAIS: O ENTRE-LUGAR DA FORMAÇÃO DE PROFESSORES ALFABETIZADORES
}

\author{
PEDAGOGICAL PRACTICE AND DIGITAL TECHNOLOGIES: THE BETWEEN- \\ PLACE OF TEACHER TRAINING LITERACY TEACHERS
}

\author{
VOOS,Jordelina Beatriz Anacleto ${ }^{1}$
}

\section{Resumo}

Apresenta-se, neste artigo, o resultado de uma pesquisa cujo objetivo central era identificar os conhecimentos sobre as Tecnologias de Informação e Comunicação - TICs, dos acadêmicos do Curso de Pedagogia que participam do Programa Institucional de Bolsa de Iniciação à Docência - PIBID, como subsídio para a alfabetização de crianças. 25 foram os acadêmicos selecionados. Os procedimentos sustentaram-se na abordagem quantitativa, mediante a aplicação de um questionário constituído de vinte e três questões. Dos resultados infere-se que, apesar do acesso à informação e da legislação apontar para a necessidade do domínio das TICs, no âmbito da formação de professores, em face das demandas do século XXI, os conhecimentos que os pedagogos, em formação, dominam são insuficientes para promovê-las no processo de alfabetização de crianças.

Palavras-chave: Alfabetização; Tecnologias; Formação de Professores.

\begin{abstract}
Presented in this article, the result of a research whose central objective was to identify the knowledge about information and communication technologies - ICT, Pedagogy course scholars participating in the Institutional Program of Scholarship of Teaching BeginnersPIBID, as subsidy for children's literacy. 25 were selected academics. The procedures stated in quantitative approach, through the application of a questionnaire consisting of twenty-three issues. The results shows that, despite the access to information and of the legislation point to the need for the domain of ICTs, in the context of teacher training, in the face of the demands of the 21 st century, the knowledge which the pedagogues, form, rule is insufficient to promote them in the process of literacy for children.
\end{abstract}

Keywords: Literacy; Technologies; Training of Teachers.

\footnotetext{
${ }^{1}$ Doutora em Engenharia de Produção pela UFSC. Doutora em Educação pela PUCRS. Professora dos Cursos de Licenciatura da UNIVILLE. Coordenadora do Grupo de Pesquisa em EducaçãoGRUEPE/UNIVILLE. jovoos@gmail.com.
}

Criar Educação, Criciúma, v. 6, no1, julho/novembro 2016.- PPGE - UNESC 


\section{CONSIDERAÇÕES INICIAIS}

Educação, ciência e tecnologia são temas, em pauta, nos seminários, congressos, encontros de educadores e também nos espaços de formação, especialmente nos cursos de formação continuada, como na pós-graduação, espaço onde mais se discute sobre as implicações futuras da produção científica a serviço da criação de inovações tecnológicas, no campo educacional. A gama de conhecimentos científicos traduzidos em inovação tecnológica ampliou-se de tal forma, nas últimas décadas, que tem assombrado os educadores.

Entretanto, entre o assombro e a necessidade, educadores comprometidos com a formação de outros, estão em busca de caminhos que possam, embora provisoriamente, orientar a direção de uma prática pedagógica que contemple a mediação auxiliada pelas tecnologias, visto que estes artefatos compõem o cotidiano dos educandos sejam eles, crianças, jovens e/ou adultos.

Na ótica de Aretio (2012, p. 9) "La información, La comunicación, laeducación y El conocimiento son esenciales para la iniciativa, elprogreso y elbienestar de las sociedades", repercutem em todas as dimensões do fazer humano, especificamente sob a forma de tecnologias digitais, pela capacidade de superar ou reduzir as consequências de muitos obstáculos tradicionais, como os de tempo e de distância. E, a aplicação do produto da ciência,a inovação tecnológica, é traduzida como um método, um saber, um meio de criação, produção e fabricação de instrumentos queem muito contribui para a resolução de problemas e satisfação de necessidades, eminentemente humanas, no caso, a educação.

Nesse sentido, entende-se que as tecnologias digitais potencializam as formas de educação, formal esistemática e/ou informal e assistemática. Representam a possibilidade do sujeito educador-educando ampliar horizontes, desenvolver-se intelectualmente, exercer sua cidadania, participar da produção dos bens culturais e intervir socialmente. Esta é a expectativa!

Em informe, apresentado pelo The New Media Consortium (NMC), Centro Superior para La Enseñanza Virtual (CSEV) e Virtual Educa (2013), as perspectivas tecnológicas para o período compreendido ente 2013-2018, no contexto da América Criar Educação, Criciúma, v. 6, nº1, julho/novembro 2016.- PPGE - UNESC 
Latina, apontam a ampliação do uso massivo da tecnologia digital, por ter se transformado rapidamente em una tecnologia acessível e disponível para qualquer pessoa, convertendo-se em una opção atrativa para as instituições e os educadores. Embora esta notícia seja alvissareira, na Revista da Sociedade Brasileira de Computação (2013, jul., p.11-12) no texto de Mota, quanto ao emprego das tecnologias, fica evidente o descompasso entre as práticas educacionais e as relações sociais, hábitos e costumes cotidianos no trabalho, no ambiente doméstico e nos acessos aos serviços em geral. Do ponto de vista exclusivamente educacional, as transformações ainda são incipientes dentro das escolas. Como consequência, afirma o autor que "o baixo nível educacional e as metodologias não compatíveis com as demandas do mundo contemporâneo podem limitar, de forma definitiva, as possibilidades de uma nação ter um desenvolvimento econômico e social sustentável”.

Mas, apesar deste descompasso, o acesso livre aos conteúdos digitais e científicos está tendo apoio e projetos envolvendo o desenvolvimento e a disponibilização de Recursos Educacionais Abertos (REAs - materiais de ensino, aprendizagem ou pesquisa, de domínio público ou disponibilizado sob uma licença de propriedade intelectual que permita seu livre uso e adaptação por terceiros - ou de direitos autorais reservados - proprietários), vêm se consolidando no cenário mundial, em face da necessidade de se ampliar o acesso à educação com custos reduzidos e como um modelo para práticas educacionais inovadoras.

Nessa perspectiva, a sociedade tecnológica do século XXI, promoverá o rompimento de fronteiras, na pesquisa, na inovação, na cultura, no mercado, na criação de novas oportunidades de relacionamento entre os humanos e nas novas maneiras de saber, ser e conviver. Não há, então, como desvincular as práticas sociais das práticas pedagógicas. Os modelos tradicionais de educação não deixarão de existir, mas irão conviver com modelos emergentes de "ensinagem"² cada vez mais presentes na sociedade do conhecimento científico e tecnológico.

Santos (2013, p. 1-2), assinalaque a educação aberta existe há muitas décadas. Hoje está reconfigurada a partir dos avanços da tecnologia, intensificada a partir da

\footnotetext{
2 Termo cunhado por ANASTASIOU, Lea das Graças \& ALVES, Leonir Pessate. Processos de ensinagem na universidade. Joinville: Editora UNIVILLE, 2007. ISBN: 97885-87977-1.

Criar Educação, Criciúma, v. 6, nº1, julho/novembro 2016.- PPGE - UNESC
} 


\section{CRIAR EDUCAÇÃO \\ Revista do Programa de Pós-Graduação em Educação - UNESC}

década de 70. A Universidade Aberta Britânica (UK Open University) e mais recentemente o Sistema Universidade Aberta do Brasil (UAB), são exemplos de que a prática de educação aberta está relacionada à inovação, "aberta às pessoas, lugares, métodos e ideias" (grifo da autora), e caracteriza-se como acesso ao conhecimento, às formas de aprender, às tecnologias de ensino, aos sistemas de ensino, aos modelos de gestão educacional, à liderança e à certificação.

Mesmo que o acesso à informação esteja ao alcance de todos, à rede mundial, de acordo com Campos (Web, 2014), devido à própria estrutura de hipertexto da rede mundial e ao uso de interface gráfica, surgem barreiras que dificultam e, às vezes, impedem o acesso de pessoas que têm algum tipo de deficiência ou dificuldade, inclusive daquelas que não vivem a cultura do contexto informatizado.O que Aretio (2012) conceitua como brecha digital ${ }^{3}$, isto é, a separação que existe entre as pessoas (comunidades, estados, países...) que utilizam as tecnologias de informação e comunicação, no seu dia-a-dia, as que não têm acesso às mesmas e as que, embora tenham, não sabem como usá-las.

Acrescenta-se à problemática, os estudos sobre a formação docente para o uso educacional das tecnologias da informação e comunicação -TICs, citados por Pesce (2013). Entre os seus achados encontram-se: a) o documento referência da $\operatorname{CONAE}^{4}$ (2010) apontando a necessidade do domínio das TICs, no âmbito da formação inicial e continuada, dos professores, em face das demandas do século XXI; b) o resultado da pesquisa de Brito (2006), sobre a percepção dos professores em relação àsTICs que, nos cursos de formação, se restringem ao uso do computador na escola, indicando a concepção de tecnologia como instrumento, como produto e não como processo e,c) as pesquisas de Gatti et all. (2009; 2011) argumentando sobre a relevância do uso pedagógico das TICs na formação de professores da Educação Básica, além da legislação pertinente, que traz explicitamente o entendimento, do "domínio das tecnologias da informação e comunicação adequadas ao desenvolvimento de aprendizagens significativas"

\footnotetext{
${ }^{3}$ Para aprofundar, recomenda-se a obra de SERRANO. Arturo \& MARTINEZ Evelio. La brecha digital: mitos y realidades. México, 2003. Editorial UABC. ISBN 970-9051-89-X www.labrechadigital.org

${ }^{4}$ CONAE - Conferência Nacional de Educação - 2010.

Criar Educação, Criciúma, v. 6, no1, julho/novembro 2016.- PPGE - UNESC
} 


\section{CRIAR EDUCAÇÃO}

Revista do Programa de Pós-Graduação em Educação - UNESC

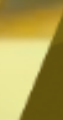

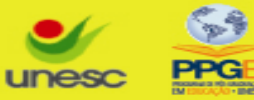

(Diretrizes Curriculares Nacionais para o curso de Pedagogia (BRASIL, 2006, artigo $5^{\circ}$., inciso VII).

Entre a riqueza da fabricação de discursos e da produção tecnológica encontram-se os saberes e fazeres dos docentes como possibilidade de inovação pedagógica. Neste entre-lugar delineia-se a questão problema: quais são os conhecimentos sobre tecnologia digital que os pedagogos já dominam para que possam promover o uso pedagógico das TICs, no processo de alfabetização de crianças?

\section{Alfabetização digital}

Nos documentos oficiais que tratam do currículo da Educação Básica, cujo foco, nos anos iniciais do Ensino Fundamental é a alfabetização, ao que parece não se encontra muito claro o conceito. Por exemplo, nos Parâmetros curriculares Nacionais (PCN1998) e nas Diretrizes Curriculares Nacionais para a Educação Básica (07/2010) alfabetizar refere-se aos domínios da leitura, da escrita e do cálculo; da leitura como compreensão e da escrita como produção de textos. Desta forma, não está explícito que habilidades desenvolver no processo de alfabetização, diferente do que se entende: a leitura só tem sentido se o sujeito desenvolveu a habilidade de reconhecer as palavras e na escrita, transcrever os sons da fala. Sintetizando: decodificando fonemas em grafemas e vice-versa. Assim, ler é compreender, e escrever é comunicar. Aprender a ler e a escrever envolvem três níveis de competência, como apresenta Oliveira (2005, p. 337), no quadro abaixo:

Quadro 1 - Níveis de desenvolvimento do processo de alfabetização

\begin{tabular}{|lll|}
\hline $\mathbf{N}$ & $\begin{array}{l}\text { Decodificar, isto é, produzir o som } \\
\text { da palavra indicado pelas letras }\end{array}$ & $\begin{array}{l}\text { Caligrafia: escrever de forma } \\
\text { legível e com fluência }\end{array}$ \\
\hline $\mathbf{2}$ & $\begin{array}{l}\text { Identificar automaticamente } \\
\text { a palavra }\end{array}$ & $\begin{array}{l}\text { Ortografia: escrever respeitando } \\
\text { regras ortográficas }\end{array}$ \\
\hline $\mathbf{3}$ & Ler com fluência & $\begin{array}{l}\text { Sintaxe: escrever frases com } \\
\text { sentido e ordenação adequada }\end{array}$ \\
\end{tabular}

Fonte: Avaliação em Alfabetização, Oliveira (2005, p. 337).

Criar Educação, Criciúma, v. 6, №1, julho/novembro 2016.- PPGE - UNESC 
$\mathrm{Na}$ composição do quadro, interpretando a descrição dos níveis e utilizando as referências do Indicador de Alfabetismo Funcional - INAF - os analfabetos não fazem a leitura de palavras e frases, embora, uma parcela destes, reconheçam números familiares, como por exemplo, números de telefone, de ônibus, tabela de preços, marcas de alimentos, bebidas, placas...; os alfabetizados em nível rudimentar são capazes de localizar informações explícitas em textos curtos e familiares: anúncio, bilhete, receitas, propagandas... Leem e escrevem números usuais, resolvem situações-problema, que envolvem operações simples, especialmente, com dinheiro em pequenas quantias; os alfabetizados em nível básico leem e compreendem textos de média extensão, localizam informações com pequenas inferências, leem números na casa dos milhões, resolvem problemas envolvendo uma sequência simples de operações e têm noção de proporcionalidade; os alfabetizados em nível pleno não apresentam restrições as habilidades de compreensão e interpretação de textos, analisam e relacionam suas partes, comparam e avaliam informações, distinguem fato de opinião, realizam inferências e sínteses e, quanto ao cálculo, interpretam mapas, tabelas e gráficos, resolvem problemas mais complexos.

O que constitui o processo de alfabetização seria o de favorecer o desenvolvimento destas habilidades em nível pleno, as quais se consolidam quando o sujeito se apropria do nível de fluência necessário à sua autonomia na leitura, na escrita e na aritmética, minimizando a exclusão de práticas sociais, cotidianas, em razão da vida em uma sociedade grafocêntrica.

Cabe registrar que, com relação aos níveis de alfabetização, nos dados publicados pelo INAF em julho de 2012, dos brasileiros entre 15 e 49 anos, o índice é de $20 \%$ de analfabetos funcionais; entre a alfabetização rudimentar e o nível básico estão $50 \%$ e, somente, $30 \%$ com a alfabetização plena.

Retomando o pensamento de Aretio (2012, op. cit.)quando trata da desigualdade com relação ao acesso a ferramentas e suportes que estão limitados a determinadas pessoas e setores da população, enseja-se a ideia de que as tecnologias digitais, utilizadas adequadamente, favoreceriam processos de inclusão, rompendo a lógica escolar da alfabetização, inserindo educandos-educadores no cotidiano digital, "para Criar Educação, Criciúma, v. 6, no1, julho/novembro 2016.- PPGE - UNESC 
uma participação efetiva e competente nas práticas sociais e profissionais que envolvem a língua escrita [...], do saber ler e escrever [...], do ser capaz de fazer uso da leitura e da escrita" (SOARES,2004, p 4-5).

Entretanto, sabe-se pelas pesquisas já apontadas que tanto as escolas como os educadores estão, ainda, pouco preparados, em termos de alfabetização digital, para realizar essa ruptura. Embora, a maioria das escolas básicas jápossua os ambientes informatizados, as tecnologias digitais não estão adequadas ao processo de alfabetização. Acrescenta-se, não estão adequadas à alfabetização digital, também, pois alfabetização digital, erroneamente está, para muitos, entendida como habilidade para usar o mouse, apontar, arrastar, cortar, colar, copiar, digitar um texto, no computador, e ler na Internet.

Porém se, como diz Freire (1983, p. 11-12),"a leitura do mundo precede a leitura da palavra, daí que a posterior leitura desta não possa prescindir da continuidade da leitura daquela. Linguagem e realidade se prendem dinamicamente", complementando com Aretio (2012, p.47):

La sociedade elconocimiento es aquellaenla que los procesos de desarrolloindividual y social se asientan sobre la construcción compartida designificados eninteracciónconel mundo físico, tecnológico y social en que los individuos se desenvuelven.

A alfabetização digital, além da iniciação ao uso e à compreensão dos recursos da informática (saberes sobre operação de máquinas e equipamentos), como em qualquer sistema de comunicação, contém linguagens cujos sentidos e significados não estão explícitos de modo imediato na leitura, para o reconhecimento das informações disponíveis. São construções complexas que caracterizam a sociedade e representam contextos de leitura ou de objeto de qualquer alfabetização, por isso se faz necessária a interlocução entre o conhecimento da ciênciapedagógica e da ciência da computação, para adentrar na sociedade da informação e do conhecimento.

\section{O PERCURSO}

Criar Educação, Criciúma, v. 6, nº1, julho/novembro 2016.- PPGE - UNESC 


\section{CRIAR EDUCAÇÃO}

Revista do Programa de Pós-Graduação em Educação - UNESC
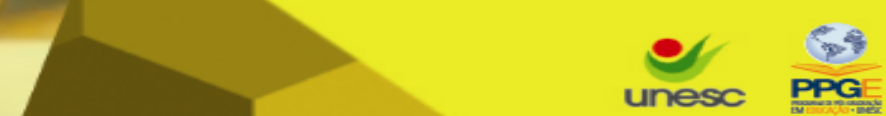

Partindo da questão problema, tendo como objetivo central do estudo identificar, quais são os conhecimentos sobre tecnologia digital que os pedagogos já dominam para que possam promover o uso pedagógico das TICs, no processo de alfabetização de crianças, julgou-se que o tipo de pesquisa mais adequado seria um levantamento, no âmbito do paradigma quantitativo.

O universo da investigação foi o curso de pedagogia, da Universidade da Região de Joinville - UNIVILLE. Constituiu a amostra, selecionada intencionalmente, 25 acadêmicos integrantes do Programa Institucional de Bolsa de Iniciação à Docência - PIBID. Para a coleta de dados foi elaborado um questionário com 23 questões.

Três etapas subsidiaram o processo: a) a exploratória, na seleção dos participantes, na definição do instrumento, na composição das questões; b) a de coleta de dados; c) a análise e interpretação dos resultados, tendo como parâmetro a estatística descritiva, levando-se em conta o significado da quantificação no contexto em que os dados foram produzidos e a área em que os problemas estudados se situam segundo Gatti (2004).

Dos 25 acadêmicos selecionados, 20 responderam, correspondendo a $80 \%$ da amostra selecionada. Este percentual respalda a significância dos resultados.

$\mathrm{Na}$ primeira questão o respondente se identificava ao confirmar o acesso ao link (https://docs.google.com/forms/d/1MPmeeelEflecZTFBV4nKcC6SnWCBlo11JMXnB BJiY_E/viewform?c=0\&w=1\&usp=mail_form_link) para responder o questionário. $\mathrm{Na}$ segunda, identificava o curso, no caso, o curso de pedagogia e, em seguida,a terceira questão correspondia à idade dos estudantes. De 19 a 36 anos é a idade dos respondentes. A média ficou entre 23 e 24 anos.

$\mathrm{Na}$ quarta e ana quinta questão interessava saber se os estudantes tinham acesso e ou possuíam computador. Conforme o que foi assinalado todos os estudantes do curso têm computador.Notebook é tipo de computador mais utilizado pelos acadêmicos, em seu cotidiano, correspondendo a $86 \%$. Os demais, $14 \%$ utilizam desktop, em seus lares ou ambientes de trabalho. Eo tipo de conexão com a internet, o índice de $79 \%$ indica que a maioria tem acesso à internet, banda larga. $21 \%$, ainda, usam o processo de discagem.

Com relação ao tempo que os acadêmicos, do curso de pedagogia, ficam conectados à internet durante o dia, conteúdo das questões seguintes, constatou-se Criar Educação, Criciúma, v. 6, nำ1, julho/novembro 2016.- PPGE - UNESC 


\section{CRIAR EDUCAÇÃO}

Revista do Programa de Pós-Graduação em Educação - UNESC

que, entre os 20 respondentes,50\% permanecem conectados de 3 a 6 horas; $20 \%$ de 5 a 10 horas; $5 \% 12$ horas e $15 \%$ até 1 hora.

Sobre o celular, $100 \%$ foi o índice. Todos possuem celular, porém não utilizam todos os aplicativos disponíveis. São os aplicativos das redes sociais os mais acessados, sendo, pela ordem: WhatsApp, Facebook,Messenger,Gmail e Skype. Em segundo plano está a pesquisa no Google e4shared. Para entretendimento utilizam Youtube, Netflix e Yupi jogos.

Foi investigado, também, se os acadêmicos possuíam tablets. Um não respondeu. Dos 19 respondentes, apenas 2, representando 10,5 \% dos sujeitos pesquisados que possuem o artefato.

Tendo em vista que nas escolas públicas da rede municipal de ensino de Joinville (SC), está sendo utilizado como recurso pedagógico, o tablet, pelos alunos do Ensino fundamental, o foco, na questão 11 era saber se, mesmo não possuindo o artefato, os acadêmicos tinham conhecimento quanto à sua usabilidade. As respostas dos acadêmicos surpreenderam. Somente 47\% assinalaram afirmativamente. 53\% desconhecem o manuseio e a aplicabilidade como recurso pedagógico. 3 não responderam esta questão.

Em se tratando de recursos, com referência à utilização de aplicativos, destacou-se o WhatsApp com 49\%,Skype 26\%, HereMaps14\%,Facebook 43\%, Instagram17\%,e Twitter $10 \%$ dentre as opções assinaladas.

Considerando a importância da disponibilidade de espaços na web, como o do blog, que pela forma e estrutura muito simples possibilita a interatividade entre pessoas por meio do registro de fatos, ideias e opiniões, foi perguntado se os acadêmicos se valiam deste espaço. Dos 20 respondentes, apenas 3 fizerem referência ao blog, correspondendo a $15 \%$.

Foi investigado também se, não tendo um blog em seu nome, saberia como utilizálo. $41 \%$ respondeu afirmativamente, mas a maioria, $59 \%$ respondeu que desconhece como criar um blog, atualizar e utilizar como recurso pedagógico.

As respostas à questão 16, revelou o desconhecimento de $95 \%$ dos acadêmicos sobre o conceito,(criado pela Free Software Foundation) de que qualquer programa de computador que pode ser usado, copiado, estudado, modificado e redistribuído, com algumas restrições, é um software livre.Na questão seguinte sobre os softwares Criar Educação, Criciúma, v. 6, nº1, julho/novembro 2016.- PPGE - UNESC 
livresque conheciam, erroneamente, $80 \%$ dos estudantes citaram o Google. Ossoftwares livres utilizados no cotidiano dos educadores, como o Linux Educacional,NAVi,i-Educar e Prolnfo, não foram sequer mencionados.

Dos 20 que responderam a questão 18, um percentual significativo de74\% já frequentaram cursos de informática. Para os que responderam, afirmativamente, foi solicitado que descrevessem qual o conteúdo e o que aprenderam durante o curso. As respostas incidiram sobre o básico da informática, como por exemplo,usar as ferramentas do Windows: word, excel, powerpoint, paint; como acessar a internet e ao outlook.

Investigou-se, também se os acadêmicos haviam participado de outros projetos, além do PIBID, em que houvesse a preocupação com a aprendizagem sobre a utilização das TICs. Somente uma resposta confirmando a abordagem das TICs, nos projetos desenvolvidos pela UNIVILLE, dentre os 20 respondentes.

Com relação à participação em disciplinas que proporcionam aprendizagens das TICs, os pibidianos fizeram referência à disciplina ministrada no curso de pedagogia. Assim, expressou uma respondente:

Estamos em andamento com essa temática nas aulas de Educação, Tecnologia e Mediação Pedagógica, no $4^{\circ}$ ano de pedagogia. Estamos lendo e discutindo bastante a respeito das TICs [...], desenvolvendo e aprendendo algumas habilidades e metodologias de ensino para a aproximação efetiva das tecnologias em sala de aula.

As questões 22 e 23 tratavam de identificar quais os conhecimentos sobre tecnologia que os pedagogos já haviam construído ao longo do curso de graduação equais as habilidades que já haviam desenvolvido, especialmente,relacionadas às tecnologias digitais.

As respostas ratificaram o que já havia sido confirmado nas questões anteriores. A maioria citou o propósito de aprimoramento no uso de ferramentas do computador, como o Windows, e os recursos da Internet, para a realização de pesquisa, digitação e formatação de textos, no sentido de apresentação dos trabalhos acadêmicos. Alguns fizeram referência à edição de vídeo com apoio do aplicativo Windows Moviemaker e Dropbox, para armazenamento de trabalhos, pesquisas, fotos, entre outros, além de mencionada a utilização de ferramentas da 
plataforma do site da UNIVILLE. Uma acadêmica relatou que aprendeu a fazer um site e,outra, um blog.

Chamou à atenção a crítica velada aos professores que não sabem utilizar as TICs, mas como o site da UNIVILLE exige esta habilidade, os acadêmicos que já dominam algumas ferramentas se dispõem a auxiliá-los. Nesse caso, esses professores "têm muito pouco a contribuir e não incentivam o uso das TICs" (registro da resposta de uma acadêmica). "Apenas estou me aperfeiçoando quando utilizo esses conhecimentos, mais o que eu sei já havia apendido antes da faculdade. Aqui, durante o curso, não adquiri nenhum outro tipo de conhecimento" (registro da resposta de outra acadêmica).

Entretanto, em um percentual de 40\%, ficou evidenciado o interesse em aprender, sobre as TICs, na disciplina de Tecnologia e Mediação Pedagógica, ministrada no $4^{\circ}$ ano do curso de Pedagogia, como por exemplo:"algumas formas de trabalhar com as crianças e ter um olhar mais cuidadoso no uso das tecnologias" (registro da resposta de uma acadêmica).

Outros depoimentos significativos trazem à tona a questão do desafio da articulação das TICs, muito utilizadas como lazer, com a aprendizagem de conceitos e conteúdos curriculares e da compreensão do processo de obsoletização de ferramentas e artefatos, nem sempre tratados pelos educadores."As nossas escolas, na sua maioria, possuem professores que estão ainda trabalhando na era analógica. Ou seja, não incorporaram na sua atividade docente práticas que incluam o ciberespaço como meio alternativo/complementar para trabalhar com seus alunos" GIRAFFA, 2013. P. 102).

Para finalizar, vale transcrever o depoimento de um respondente: "este mundo virtual que está tão presente em nosso cotidiano e principalmente nas vidas de muitos acadêmicos e crianças é o grande desafio da educação em nosso país".

\section{CONSIDERAÇÕES FINAIS}

Apesar de ter realizado um exercício, muito preliminar, em virtude da exiguidade do tempo, é possível inferir que a distância que separa os educadores formadores e os professores em formação, em matéria de tecnologia, com foco nas tecnologias Criar Educação, Criciúma, v. 6, nำ, julho/novembro 2016.- PPGE - UNESC 


\section{CRIAR EDUCAÇÃO}

Revista do Programa de Pós-Graduação em Educação - UNESC 7

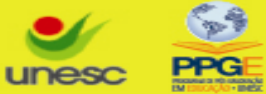

digitais é maior do que se imaginava. Os resultados da pesquisa traduzem esta distância. Não há como discordar de Mota (2013, p.10) que,

nos processos educativos contemporâneos uma exigência adicional é preparar futuros profissionais e cidadãos em geral para um mundo em permanente transformação, onde a utilização de tecnologias digitais, mais do que uma possibilidade, se mostra uma necessidade.

Entretanto, ainda, na perspectiva deste interlocutor, é uma visão ingênua acreditar que a facilidade ao acesso à informação e à incorporação das novas tecnologias digitais, ao cotidiano das pessoas em suas práticas sociais, é suficiente para promover a apropriação de conhecimentos necessários à formação e profissionalização. Ou, contraditoriamente, a restrição ao uso, nas escolas, haja vista a eficácia questionável. Este posicionamento não favorece o aproveitamento das potencialidades das TICs. Este fato, explica-se, na ótica de Giraffa (2009, p. 21). "A escola, tradicionalmente, leva mais tempo para absorver e incorporar as tendências e ofertas tecnológicas".

No caso, em estudo, cotejando o referencial teórico e os resultados da pesquisa, infere-se que, apesar do acesso à informação ao alcance de todos, apesar da legislação pertinente apontar para a necessidade do domínio das TICs, no âmbito da formação inicial e continuada, dos professores, em face das demandas do século XXI, na universidade, em um curso de formação de pedagogos, tornam-se pertinentes as considerações de Aretio (2012) a respeito da brecha digital e as de Pesce(2013, apud BRITO, 206) quando aludem que nos cursos de formação, em pauta, o domínio das TICs se restringem ao uso do computador, indicando a concepção de tecnologia como instrumento e como produto, não como meio, para alavancar o processo de aprendizagem.

Fazendo, um contraponto com o conceito de alfabetização, delineado anteriormente, e a descrição dos níveis, utilizando as referências do Indicador de Alfabetismo Funcional - INAF, não seria exagero afirmar que em matéria de alfabetização digital, entre a alfabetização rudimentar e o nível básico, os pedagogos e os professores formadores encontram-se no patamar de 50\%. Desse modo, os conhecimentos sobre tecnologia digital que os pedagogos, em formação, dominam são insuficientes para promovê-las o processo de alfabetização de crianças.

Criar Educação, Criciúma, v. 6, nำ1, julho/novembro 2016.- PPGE - UNESC 


\section{CRIAR EDUCAÇÃO}

Revista do Programa de Pós-Graduação em Educação - UNESC

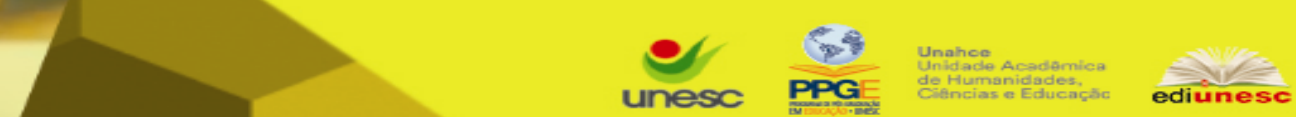

É preciso reconhecer que este estudo necessita de aprofundamento. Estas considerações são preliminares e o adensamento se faz necessário. Entretanto, alguns indicadores evidenciam a fragilidade do processo formativo de professores alfabetizadores, à luz do avanço científico e tecnológico. Esperava-se que no entrelugar "a confluência da riqueza da fabricação de discursos e da produção tecnológica" (grifo da autora) se encontrassem os saberes e fazeres dos docentes, em TICs, como possibilidade de inovação pedagógica, mediando o processo de alfabetização das crianças.

Sería de desear que en todos los países e instalaciones educativas (muchosestánlejos de lograrlo) nuestrosniños y adolescentes finalizasen sus estúdios de enseñanza primaria, cuánto más de la secundaria, plenamente alfabetizados enlaimprescindiblelectoescritura, enelinevitablelenguaje audiovisualy en todo lo que suponenlosnuevos códigos tecnológicos e informacionalede los sistemas digitales, cada vez más necesarios. Este último tipo de alfabetización, la digital, debería permitir a quienessalen delaescueluna relación y participaciónconlosotrosmiembros que pueblanlared, utilizando lasherramientasapropiadas para cada tipo de relación o actividadque se deseeemprender. Los filtros que desde laescuela se pueden estabelecer sinduda que enriqueceránel uso ideal de dispositivos, herramientas y aplicacionesPero no se trata sólo de introducir TIC enlasescuelas, porque essas TIC puedenagregarse a laactividadordinariadel centro como un recursosmás para hacerlomismoquizás de otramanera 0 , sin embargo, puedenintegrarseenelprocesos para hacernuevas cosas conprocedimientostambiénnuevos, es decir, utilizando lastecnologíasdigitalesconnuevos enfoques metodológicosy extrayendo de ellas toda la riqueza que puedenaportarnos paraalcanzarlas finalidades educativas propuestas y otras valiosas que sindudasurgirán (ARETIO,2012 p.10) 


\section{- $=$ \\ unesc PPG

\section{REFERÊNCIAS}

ARETIO, Lorenzo García.Sociedaddelconocimiento y educación. Madrid: Librería UNED,Universidad Nacional de Educación a Distancia, 2012.

BRASIL, Ministério da Educação. Parâmetros Curriculares Nacionais, 1998.

Ministério da Educação. Diretrizes Curriculares Nacionais para a Educação Básica. Resolução 07/2010.

CAMPOS, Márcia de Borba. Promoção da acessibilidade na Web como recurso parainclusão e permanência de acadêmicos com necessidades educacionais especiais. Pontifícia Universidade Católica do Rio Grande do Sul (PUCRS). Anais do SBIE, 2006. Disponível em: www.br-ie.org

Acesso em: Abril de 2016

GATTI, Bernadete. Estudos quantitativos em educação. In Pesquisa, São Paulo, v.30, n.1, p. 11-30, jan./abr. 2004.

Educação e

GIRAFFA, M Lucia. Jornada nas Escol@s: A nova geração de professores e alunos. In Revista Tecnologias, Sociedade e Conhecimento, vol. 1, n. 1, nov/2013.

, Uma odisseia no ciberespaço: o software educacional dos tutoriais aos mundos virtuais. In Revista Brasileira de Informática na Educação, v. 17, n. 1, 2009.

FREIRE, Paulo. A importância do ato de ler. São Paulo: Autores Associados, 1989.

JOHNSON, L., ADAMS Becker, S., GAGO, D. Garcia, E., y MARTÍN, S..In NMC Perspectivas Tecnológicas: Educación Superior en América Latina 2013-2018. UnAnálisis Regional del Informe Horizondel NMC. Austin, Texas: The New Media Consortium, 2013. Disponível: http://creativecommons.org/licenses/by/3.0/. Acesso em: Janeiro de 2016.

MOTA, Ronaldo. Educação no contexto das tecnologias digitais. In Revista da Sociedade Brasileira de Computação. n 2, jul 2013. SBC: Porto Alegre, RS. Disponível em: www.sbc.org.br. Acesso em: Janeiro de 2016.

OLIVEIRA, João Batista Araujo. Avaliação em alfabetização.In: Revista Ensaio: aval. pol. públ. Educ., Rio de Janeiro, v.13, n.48, p. 375-382, jul./set. 2005.

PESCE, Lucila. A potência didática dos recursos educacionais abertos para a docência na contemporaneidade. In Revista Eletrônica de Educação, v. 7, n. 2, 2013, p. 195-210. Artigos. ISSN 1982-7199. Programa de Pós-Graduação em Educação, Universidade Federal de São Carlos, Brasil. Disponível em: www.reveduc.ufscar. Acesso em: março de 2016.

Criar Educação, Criciúma, v. 6, no1, julho/novembro 2016.- PPGE - UNESC 


\section{CRIAR EDUCAÇÃO}

Revista do Programa de Pós-Graduação em Educação - UNESC

SANTOS, Andreia Inamorato. O valor agregado nos Recursos Educacionais Abertos: oportunidades de empreendedorismo e inovação nas IES particulares brasileiras. In Revista Digital de Tecnologias Cognitivas. n 7, jan - jul 2013, ISSN: 1984-3585. Disponível em: www.cetic.brAcesso em: dezembro de 2015.

SOARES, Magda. Alfabetização e letramento: as muitas facetas. In .Revista Brasileira de Educação. Jan /fev/mar /abr 2004 №. 25.

Criar Educação, Criciúma, v. 6, ㄲo1, julho/novembro 2016.- PPGE - UNESC 